\title{
AERATION AT OVERFLOW DAMS WITH CURVED SURFACES BY DIFFERENT FLASHBOARD SPILLWAYS
}

\author{
Kejian Chu ${ }^{\mathrm{a}, \mathrm{b}, \mathrm{c}}$, Zulin Hua ${ }^{\mathrm{a}, \mathrm{b}, \mathrm{c}}$, Lijun Ji ${ }^{\mathrm{a}, \mathrm{c}}$ \\ ${ }^{a}$ Key Laboratory of Integrated Regulation and Resource Development on Shallow Lake of Ministry of Education, \\ College of Environment, Hohai University, Nanjing City, P. R. China \\ ${ }^{b}$ National Engineering Research Center of Water Resources Efficient Utilization and Engineering Safety, \\ Nanjing City, P. R. China \\ 'College of Environment, Hohai University, 1 Xikang Road, Nanjing City, 210098 Jiangsu Province, P. R. China
}

Submitted 27 Jun. 2013; accepted 03 Mar. 2014

\begin{abstract}
Aeration using overflow dams is an eco-friendly and economical method of improving dissolved oxygen levels in polluted urban streams. Laboratory investigations of aeration performance in smooth spillways, as well as in parallel flashboard and interlaced flashboard spillways with different flashboard intervals, for overflow dams with curved surfaces have been conducted separately. Aeration efficiencies of the different types of spillways, in particular the effects of varying discharge rate, total spillway height, and flashboard interval, have been discussed in detail. The test data illustrate that aeration efficiency in all spillways increases with spillway height and decreases with increasing discharge. Flashboard spillways appear to provide significantly higher aeration efficiency than smooth ones, and aeration efficiency increases with the number of flashboards, but with a continuously declining growth rate. By combining $F d_{s}$ with $h_{d}^{*}$, a new dimensionless parameter $\Psi$ is created to characterize the comprehensive effects of hydraulic conditions on aeration. Empirical formulas for oxygen-transfer efficiency in smooth, parallel flashboard, and interlaced flashboard spillways have been developed with $\Psi$ and the dimensionless number of flashboards per unit area of spillway $N^{*}$ as independent variables, and the properties of these formulas are discussed.
\end{abstract}

Keywords: water cleaning technologies, aeration, flashboard spillways, overflow dam with curved surface, oxygentransfer efficiency, spillway Froude number.

\section{Introduction}

Dissolved oxygen (DO) is the key important water-quality index for stream aquatic ecosystems. DO is usually lower in urban streams because they receive more pollutant inputs than rural streams. Increasing DO concentration in urban streams effectively promotes the activities of aerobic bacteria, improves the local living conditions of aquatic organisms, inactivates contaminants held in sediments, and even eliminates foul odors in water, thus contributing to improving stream ecosystems.

Artificial aeration has been widely used as an efficient oxygenation method to increase DO levels in urban streams. It can be technically divided into two categories: aeration through gas entrainment and aeration using hydraulic structures. The former approach has provided good aeration performance (Dalla Santa, Vinatea 2007;
Ghaly, Thistle 2009; Dong et al. 2009; Moulick, Mal 2009; Kumar et al. 2010), but special devices are needed to entrain or blow air (pure oxygen) into the water body, which inevitably incur excessive energy consumption and relatively high operating cost. On the other hand, hydraulic structures are often constructed across urban streams to raise the water level. Low-overflow dams and weirs are among the main types of hydraulic structures used. These overflow dams and weirs increase available DO concentrations in streams without additional gas-blowing devices, even though the water is in contact with them only for a short time (Kramer, Hager 2005; Ghare et al. 2008; Bagatur 2009; Baylar et al. 2010; Crookston, Tullis 2013).

Spillway morphology is the key factor affecting the aeration efficiency of an overflow dam, and many studies on this topic have been conducted and reported. For example, Chanson and Toombes (2002) pointed out that a flat

Corresponding author: Hua Zulin

E-mail: zulinhua@hhu.edu.cn 
stepped cascade for operation of nappe flows might be an effective means of water aeration by experimental investigation. Further laboratory studies have suggested that channel slope and step height are the important factors influencing the aeration performance of stepped chutes (Baylar et al. 2003, 2006; Takahashi, Ohtsu 2012), and mass-transfer equations were developed to predict aeration efficiency in terms of dissolved oxygen (Toombes, Chanson 2005; Baylar et al. 2007; Felder, Chanson 2009). Aeration on stepped chutes with end sills has also been explored, in particular the effects of the relative size of the end sill and the length/ depth ratio of the chute (Emiroglu, Baylar 2003). Aras and Berkun (2010) determined empirical correlations between the length of the non-aerated flow region and aeration efficiency. Moulick et al. (2010) determined experimentally the optimum number of steps, the slope of the entire cascade, and hydraulic loading rate at which the maximum overall aeration efficiency occurs for the stepped cascade.

However, previous studies have focused mainly on oxygen transfer in stepped chutes and channels. Aeration performance of overflow dams with curved surfaces - typical low hydraulic structures widely used in rivers and lakes - has been insufficiently studied. Moreover, little attention has been paid to the spillway effect on oxygen transfer at overflow dams, although this problem should be investigated in depth for optimal design of dams in terms of aeration efficiency. In this research, experimental investigations of aeration on overflow dams with curved surfaces by spillways with different morphological characteristics, including smooth surfaces, parallel flashboards, and interlaced flashboards, have been carried out. The aeration performance of flashboard spillways was investigated by varying the flow discharge $Q$, spillway height $h$, and flashboard interval $l$, and results were compared with those for smooth spillways. The effects of spillway morphology on oxygen-transfer efficiency $E_{20}$ have also been discussed. Moreover, relationships between overflow hydraulic conditions, number of flashboards, and $E_{20}$ of the various types of spillways have been established.

\section{Experimental apparatus}

The flow system is presented schematically in Fig. 1. All experiments were performed in an open rectangular organic-glass flume with a cross section of $20 \mathrm{~cm} W \times$ $30 \mathrm{~cm} \mathrm{H}$. The experimental flume consisted of an inlet section, a test dam section, and an outlet section. One $120-\mathrm{cm}$ long straight section was used as an inlet, and the test dam was $80 \mathrm{~cm}$ high, with the shape of the curved surface designed according to the Japanese Technical Standards for inflatable rubber dams. Seven spillways were fitted onto the test dam for the experiments, including one smooth spillway, three parallel flashboard spillways (with $3 \mathrm{~cm}, 6 \mathrm{~cm}$, and $9 \mathrm{~cm}$ streamwise flashboard intervals), and three interlaced flashboard spillways (also with $3 \mathrm{~cm}, 6 \mathrm{~cm}$, and $9 \mathrm{~cm}$ streamwise intervals). The flashboards are thin square plates with a side length of $2 \mathrm{~cm}$. Fig. 2 shows a schematic plot of the test dams with smooth spillway, parallel flashboard, and interlaced flashboard spillways separately.

\section{Theoretical analysis}

The overall oxygen-transfer efficiency $E$ of a hydraulic structure at any water temperature can be defined as (Toombes, Chanson 2005):

$$
E=\left(C_{2}-C_{1}\right) /\left(C_{s}-C_{1}\right)
$$

where: $C_{1}$ is the upstream DO concentration; $C_{2}$ is the downstream DO concentration; $C_{s}$ is the saturation concentration.

To account for the temperature dependence of oxygen transfer and to provide a uniform basis for comparison, the overall oxygen-transfer efficiency is normalized to a standard temperature $\left(20^{\circ} \mathrm{C}\right)$ using Eqn (2) below (Gulliver et al. 1990):

$$
\left\{\begin{array}{l}
E_{20}=1-(1-E)^{1 / f} \\
f=1.0+0.02103(T-20)+8.261 \times 10^{-5}(T-20)^{2},
\end{array}\right.
$$

where: $E_{20}$ is the oxygen-transfer efficiency at $20^{\circ} \mathrm{C}$; $T$ is the water temperature in the test.

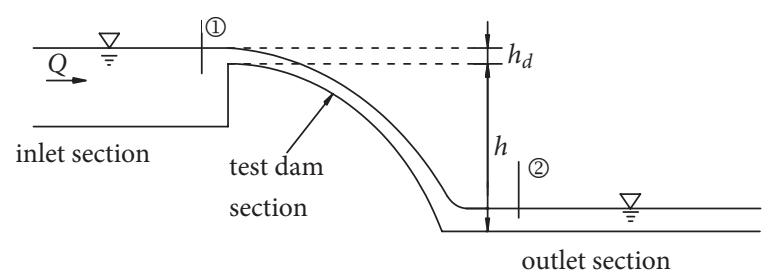

Fig. 1. Schematic diagram of the experimental apparatus
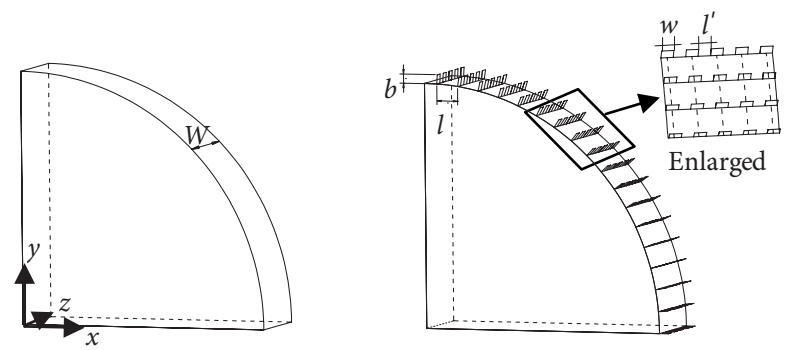

(a)

(b)

(c)

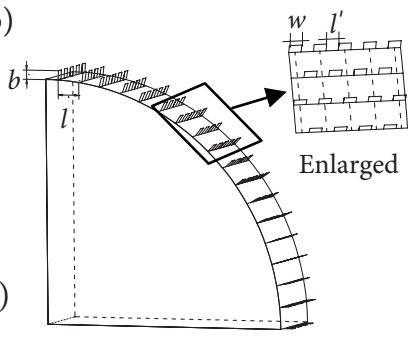

Fig. 2. Test dam with: (a) smooth spillway; (b) parallel flashboard spillway; (c) interlaced flashboard spillway 
Aeration performance of the overflow dam depends on flow conditions, spillway morphology, and experimental medium properties. Therefore, the characteristic variables affecting aeration in the present experiments can be outlined as:

$$
E_{20}=f\left(Q, h_{d}, h, L, W, b, w, l, l^{\prime}, \rho_{w}, \rho_{a}, \mu_{w}, \tau, n, g\right),
$$

where: $Q$ is the discharge rate; $h_{d}$ is the water depth on the crest of the dam; $h$ is the total height of the spillway; $L$ is the curve length of the spillway; $W$ is the width of the spillway; $b$ is the height of the flashboards; $w$ is the width of the flashboards; $l$ is the streamwise interval of the flashboards; $l$ ' is the transverse interval of the flashboards; $\rho_{w}$ is the density of water; $\rho_{a}$ is the density of air; $\mu_{w}$ is the dynamic viscosity of water; $\tau$ is the surface tension of water; $n$ is the absolute roughness of the spillway; $g$ is the acceleration of gravity.

Assuming $L, \rho_{w}$ and $g$ to be fundamental dimensions and applying the Buckingham Pi-theorem, Eqn (3) can be rewritten as follows:

$$
E_{20}=f\left(\frac{q}{\sqrt{g L} L}, h_{d}^{*}, h^{*}, \frac{L}{W}, \frac{b}{L}, \frac{w}{L}, \frac{L}{l}, \frac{l^{\prime}}{L}, \frac{\rho_{a}}{\rho_{w}}, \frac{q \rho_{w}}{\mu_{w}}, \frac{\tau}{g \rho_{w} L^{2}}, \frac{n}{L}\right),
$$

where: $q$ is the discharge per unit width, $q=Q / W ; h_{d}{ }^{*}$ is the relative depth on the crest, $h_{d}^{*}=h_{d} / L ; h^{*}$ is the relative total height of the spillway, $h^{*}=h / L$.

The experiments were conducted on the same fluids (air and tap water) and spillways of the same material at water temperatures varying from $11.8^{\circ} \mathrm{C}$ to $14.8^{\circ} \mathrm{C}$. This means that there was little change in the variables characterizing the medium properties of $\rho_{w}, \rho_{a}, \mu_{w}, \tau$ and $n$ during the test runs. Therefore, the ratios $\rho_{a} / \rho_{w}$ and $n / L$ remain almost invariant and can be dropped from Eqn (4). The term $\tau /\left(g \rho_{w} L^{2}\right)$ can also be omitted because it can be replaced by the Morton number $M o=$ $g \tau^{4} /\left(\rho_{w} \tau^{3}\right)$ (Chanson 2009). The term $q \cdot \rho_{w} / \mu_{w}$ denotes the Reynolds number and can be ignored because the overflows are always in a state of turbulent motion (Moulick et al. 2010).

The term $L / l$ characterizes the total number of flashboards in the stream direction along the spillway. The terms $L / W, l^{\prime} / L$, and $w / L$ can be combined as follows:

$$
\left[(L / W) \cdot\left(l^{\prime} / L\right)+(L / W) \cdot(w / L)\right]^{-1}=W /\left(l^{\prime}+w\right),
$$

where the term on the right-hand side of Eqn (5) can be used to characterize the total number of flashboards in the transverse direction across the spillway. The number of flashboards per unit area of spillway can thus be obtained as $N=(L / l) \cdot W /\left(l^{\prime}+w\right) /(W \cdot L)=\left[l \cdot\left(l^{\prime}+w\right)\right]^{-1}$. Using a dimensionless treatment with flashboard area, a dimensionless number $N^{\star}$ can be defined as:

$$
N^{\star}=N \cdot(b \cdot w)=b \cdot w /\left[l \cdot\left(l^{\prime}+w\right)\right] .
$$

Because the flashboard is square $(b=w)$ in this study, Eqn (6) can be rewritten as:

$$
N^{\star}=b^{2} /\left[l \cdot\left(l^{\prime}+b\right)\right] .
$$

The spillway Froude number, $F d$, can be deduced as shown below by combination of the first and third terms in Eqn (4):

$$
\begin{aligned}
& F d_{s}=\frac{q}{\sqrt{g L} L} / h^{*}=\frac{q}{\sqrt{g L} L} /\left(\frac{h}{L}\right)= \\
& \frac{q}{\sqrt{g L} L} \cdot \frac{L}{h_{d}} \cdot \frac{h_{d}}{L} \cdot \frac{L}{h}=\frac{q}{\sqrt{g L} h_{d}} \frac{h_{d}}{h}=\frac{u}{\sqrt{g L}} \frac{h_{d}}{h},
\end{aligned}
$$

where: $u$ is the average velocity at the crest. Hence, Eqn element (4) can be simplified as follows:

$$
E_{20}=f\left(F d_{s}, h_{d}^{*}, N^{*}\right) .
$$

The above equation indicates that the principal dimensionless variables determining aeration performance can be reduced to the spillway Froude number $F d_{s}$, the relative depth on the crest $h_{d}^{*}$, and the dimensionless number of flashboards per unit area $N^{*}$.

\section{Experiments and parameters}

Tap water was used throughout these experiments to avoid disturbances to aeration by surfactants, organic substances, and suspended solids in a natural stream. First, the experimental water was poured into a storage tank, allowed to stand for several hours, and then deoxygenated by the sodium sulfite method to $2.0-3.0 \mathrm{mg} / \mathrm{l}$ of dissolved oxygen (DO). Afterward, the deoxygenated water was pumped to a stilling tank and then entered the test spillways through the inlet section. During the experiments, DO concentration measurements of the water were carried out upstream (point (1)) and downstream (point (2)) of the spillways simultaneously when the flow patterns being stable (Fig. 1), using Hach 'HQ' Series portable dissolved oxygen meters with a dissolved oxygen range of $0.00-20.00 \mathrm{mg} / \mathrm{L}$ (0-200\% saturation); resolution: $0.01 \mathrm{mg} / \mathrm{L}$; and measurement precision: $\pm 0.1 \mathrm{mg} / \mathrm{L}$ (DO < $8 \mathrm{mg} / \mathrm{L}), \pm 0.2 \mathrm{mg} / \mathrm{L}(\mathrm{DO}>8 \mathrm{mg} / \mathrm{L})$. When readings of the dissolved oxygen meters were stable, 10 measuring data of $\mathrm{C}_{1}$ at point (1) and $\mathrm{C}_{2}$ at point (2) respectively were recorded in each run. The discharge flowrate and temperature of the test water were measured by an LZB- 80 glass rotor flowmeter installed in the supply line and by a digital thermometer respectively.

Throughout the experiments, the geometric size $b$ (or $w$ ), the transverse interval $l$ ' of the flashboards, and the spillway width were kept constant. With variations in either $Q$ or $h, F d_{s}$ and $h_{d}^{*}$ were changed synchronously, and variations in 1 led to variations in $N^{*}$. In this way, 175 experimental runs were designed by varying $Q, h$ at five different levels, and $l$ at three different levels, to be 
Table 1. Combinations of test conditions

\begin{tabular}{|c|c|c|c|c|c|c|}
\hline Spillway type & $\begin{array}{c}\text { Discharge } \\
\text { rate } \\
Q(1 / s)\end{array}$ & $\begin{array}{c}\text { Spillway height } \\
\text { (length) } \\
h(\mathrm{~L})(\mathrm{cm})\end{array}$ & $\begin{array}{l}\text { Stream-wise } \\
\text { interval } \\
l(\mathrm{~cm})\end{array}$ & $\begin{array}{l}\text { Width of } \\
\text { spillway } \\
W(\mathrm{~cm})\end{array}$ & $\begin{array}{c}\text { Length } \\
\text { of flash-board } \\
b(\mathrm{~cm})\end{array}$ & $\begin{array}{c}\text { Trans-verse } \\
\text { interval } \\
l^{\prime}(\mathrm{cm})\end{array}$ \\
\hline Smooth & 0.4 & $60.0(99.0)$ & - & \multirow{5}{*}{20.0} & \multirow{5}{*}{2.0} & \multirow{5}{*}{2.0} \\
\hline Parallel & 0.6 & $65.0(104.4)$ & \multirow{2}{*}{3.0} & & & \\
\hline flashboard & 0.8 & $70.0(109.7)$ & & & & \\
\hline Interlaced & 1.0 & 75.0 (114.9) & 6.0 & & & \\
\hline flashboard & 1.2 & $80.0(120.0)$ & 9.0 & & & \\
\hline
\end{tabular}

carried out on parallel flashboard, interlaced flashboard, and smooth spillways. The various combinations of test conditions are given in Table 1.

\section{Results and discussion}

Table 2. Expectation and relative standard deviation of $E_{20}$

\begin{tabular}{|c|c|c|c|}
\hline Spillway type & $\begin{array}{l}\text { Discharge } \\
\text { rate } \\
Q(1 / s)\end{array}$ & Expectation & $\begin{array}{c}\text { Relative } \\
\text { standard } \\
\text { deviation (\%) }\end{array}$ \\
\hline \multirow{5}{*}{ Smooth } & 0.4 & $0.125 \sim 0.171$ & $0.39 \sim 2.80$ \\
\hline & 0.6 & $0.125 \sim 0.163$ & $1.82 \sim 3.17$ \\
\hline & 0.8 & $0.120 \sim 0.159$ & $0.87 \sim 4.86$ \\
\hline & 1.0 & $0.116 \sim 0.157$ & $1.28 \sim 3.34$ \\
\hline & 1.2 & $0.116 \sim 0.154$ & $1.42 \sim 4.72$ \\
\hline \multirow{5}{*}{$\begin{array}{l}\text { Parallel } \\
\text { flashboard }\end{array}$} & 0.4 & $0.426 \sim 0.589$ & $0.53 \sim 2.95$ \\
\hline & 0.6 & $0.421 \sim 0.584$ & $0.50 \sim 3.62$ \\
\hline & 0.8 & $0.419 \sim 0.578$ & $1.51 \sim 4.87$ \\
\hline & 1.0 & $0.411 \sim 0.576$ & $0.65 \sim 4.02$ \\
\hline & 1.2 & $0.407 \sim 0.570$ & $1.53 \sim 3.77$ \\
\hline \multirow{5}{*}{$\begin{array}{l}\text { Interlaced } \\
\text { flashboard }\end{array}$} & 0.4 & $0.414 \sim 0.581$ & $0.81 \sim 3.25$ \\
\hline & 0.6 & $0.410 \sim 0.578$ & $0.81 \sim 3.85$ \\
\hline & 0.8 & $0.404 \sim 0.577$ & $1.00 \sim 4.12$ \\
\hline & 1.0 & $0.401 \sim 0.575$ & $2.15 \sim 3.95$ \\
\hline & 1.2 & $0.400 \sim 0.574$ & $2.08 \sim 3.71$ \\
\hline
\end{tabular}

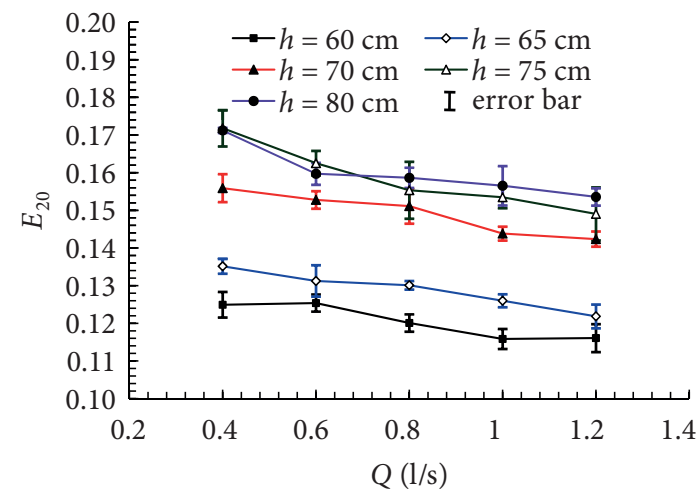

(a)

Fig. 3. Variation of oxygen-transfer efficiency $E_{20}$ for a smooth spillway: (a) $E_{20}$ vs. Q; (b) $E_{20}$ vs. $h$. The error bars reflect the standard deviations of mean $E_{20}$ derived from all measuring data in each experiment
Table 2 describes the variation ranges of mathematical expectation and relative standard deviation of the set of $E_{20}$ in each experiment, of which elements are calculated by Eqns (1) and (2) with the 10 pairs of DO measuring data respectively, at different $Q$ in the smooth, parallel flashboard, and interlaced flashboard spillways.

Figure 3 illustrates the variation in the oxygentransfer efficiency $E_{20}$ with discharge rate $Q$ and total height $h$ (and $h^{*}$ ) of the smooth spillway. In these tests, the levels of $E_{20}$ ranged from 0.116 to 0.171 . In Figure 3(a), $E_{20}$ decreases with increasing discharge rate $Q$ at the same $h$, with an overall attenuation rate (calculated by $\Delta E_{20} / \Delta Q$ ) of 0.0190 from $Q=0.4 \mathrm{l} / \mathrm{s}$ to $Q=1.2 \mathrm{l} / \mathrm{s}$. This can be explained by noting that increasing the discharge rate means increasing the flow velocity through the spillway, thus inevitably shortening the oxygen-transfer time at the air-water interface. On the other hand, $E_{20}$ increases with $h\left(\right.$ or $\left.h^{\star}\right)$ at the same $Q$ (Fig. 3(b)), which can be attributed to extension of the oxygen-transfer length from air into water. The overall growth rate of $E_{20}$ with $h^{*}$ (calculated by $\Delta E_{20} / \Delta h^{\star}$ ) is about 0.631 from $h^{\star}=0.606$ to $h^{\star}=0.667$.

By combining $F d_{s}$ with $h_{d}^{*}$, a new dimensionless parameter $\Psi$ can be created to characterize the comprehensive effects of the hydraulic conditions of the overflow on aeration in the spillway, as outlined below:

$$
\Psi=F d_{s}^{1 / 3} \cdot h_{d}^{*} .
$$

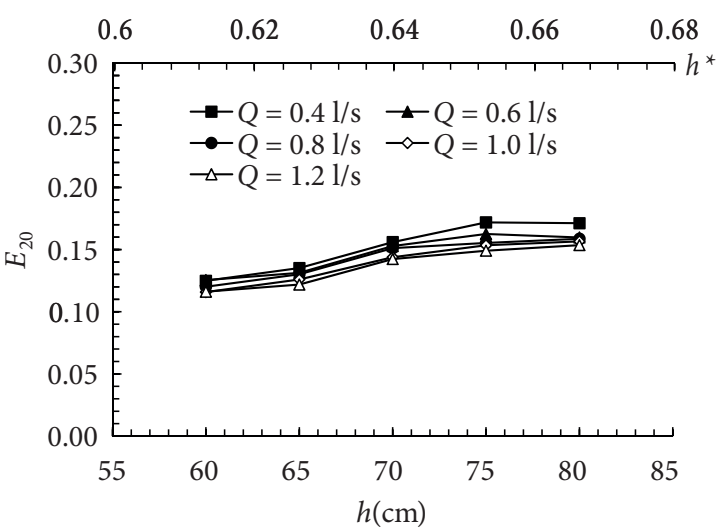

(b) 
The relationship between $\Psi$ and $E_{20}$ is displayed in Figure 4. On the whole, there appears to be an inverse relationship between the two, and the experimental correlation with $E_{20}$ as the response and $\Psi$ as the independent variable can be determined as follows:

$$
E_{20}=0.870 \times 10^{-3} \cdot \Psi^{-1} ; R^{2}=0.908 .
$$

As Eqn (11) indicates, $E_{20}$ decreases to a very small value with increasing $\Psi$. It can be determined that aeration performance is negatively correlated with discharge rate and with water depth on the crest, but positively correlated with the total height and length of the spillway. Because water flow is relatively slow and stable in urban streams,

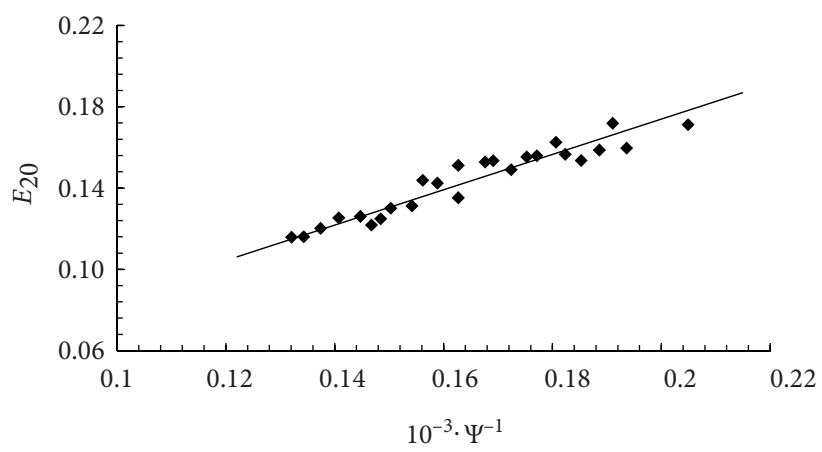

Fig. 4. Relationship between $\mathrm{E}_{20}$ and $\Psi$ for a smooth spillway increasing physical size is almost the only method available to improve the aeration capabilities of curved overflow dams with smooth spillways, but the effectiveness of this approach is rather low, and it also entails a sharp rise in reconstruction investments.

Variations of $E_{20}$ with discharge rate $Q$ and height $h$ of water through the parallel flashboard and interlaced flashboard spillways with different flashboard intervals are given in Figs 5 and 6 respectively. The trend in $E_{20}$ is similar to that observed for smooth spillways: $E_{20}$ also decreases with increasing $Q$ at the same $h$, and increases with $h\left(\right.$ or $\left.h^{*}\right)$ at the same Q. However, the range of variation for $E_{20}$ in the flashboard spillways was observed to be about 0.400 to 0.589 , which is significantly higher than the levels in the smooth spillways. The overall attenuation rate with $Q$ and growth rate with $h^{*}$ of $E_{20}$ were 0.0187 and 1.687 respectively in the parallel flashboard spillways and 0.0192 and 1.312 respectively in the interlaced flashboard spillways. On the basis of this, the rates of decrease of $E_{20}$ with $Q$ were almost the same in the smooth and flashboard spillways, but the growth rates of $E_{20}$ with $h^{*}$ actually differed from each other in the following descending order: parallel flashboard spillway $>$ interlaced flashboard spillway $>$ smooth spillway.

Comparisons of oxygen-transfer efficiency $E_{20}$ in the smooth, parallel flashboard, and interlaced flashboard

a)
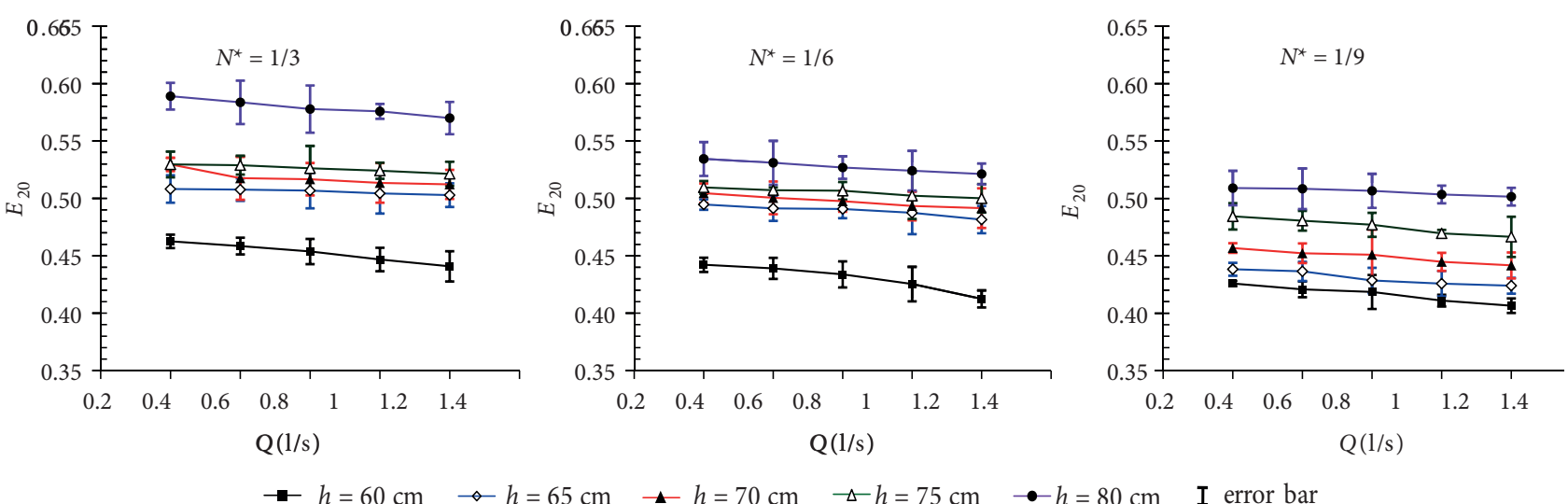

b)
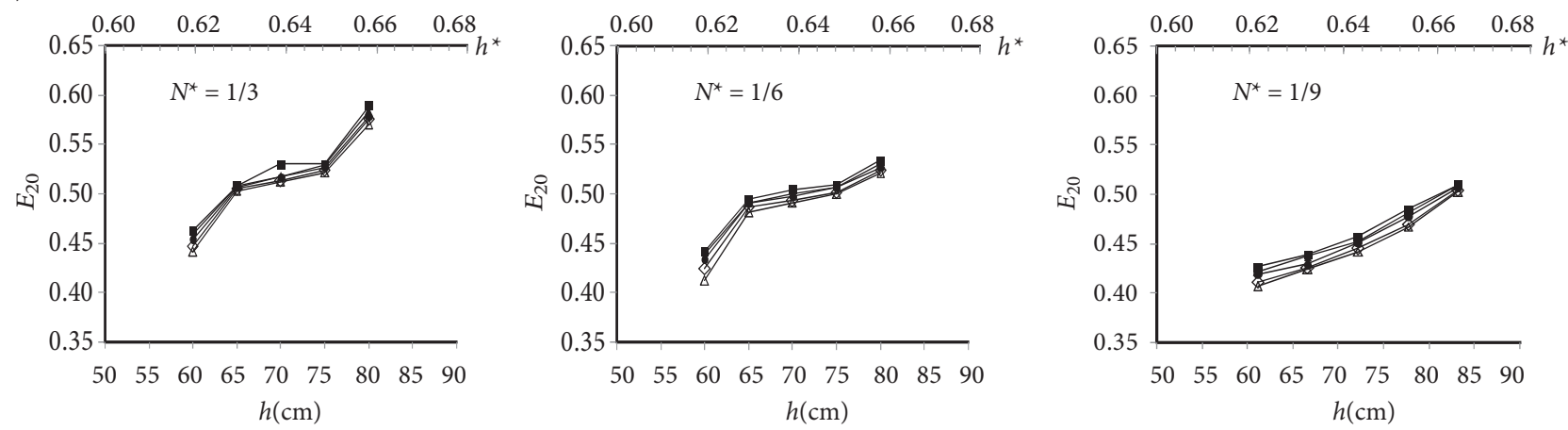

$\rightarrow Q=0.4 \mathrm{l} / \mathrm{s} \rightarrow Q=0.6 \mathrm{l} / \mathrm{s} \rightarrow Q=0.8 \mathrm{l} / \mathrm{s} \rightarrow Q=1.0 \mathrm{l} / \mathrm{s} \rightarrow Q=1.2 \mathrm{l} / \mathrm{s}$

Fig. 5. Variation of oxygen-transfer efficiency $E_{20}$ in parallel flashboard spillways: (a) $E_{20}$ vs. Q; (b) $E_{20}$ vs. $h$ 
a)
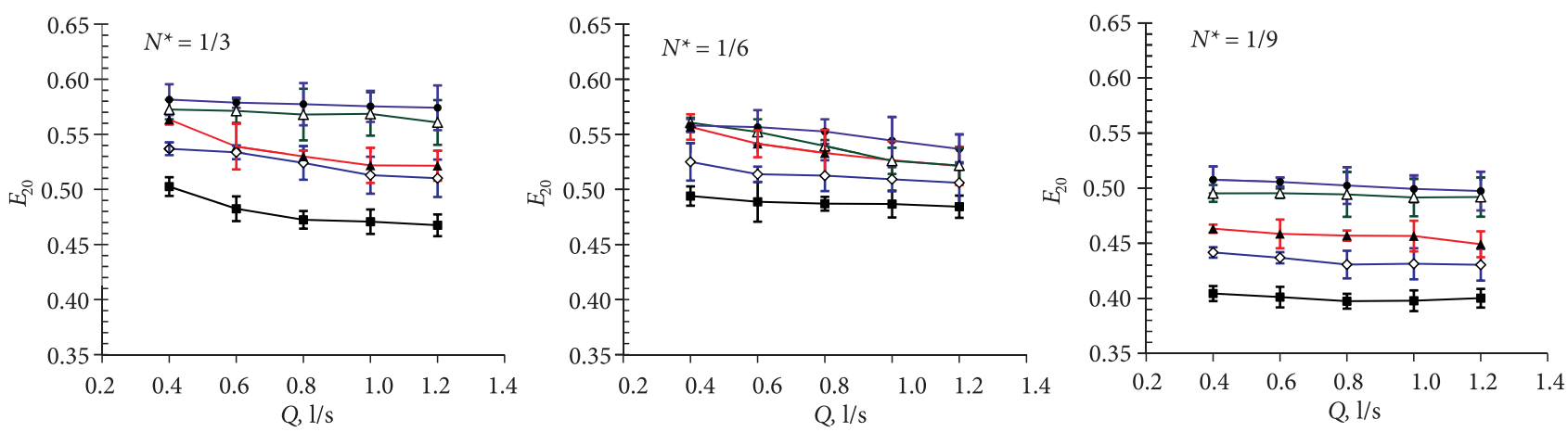

b)
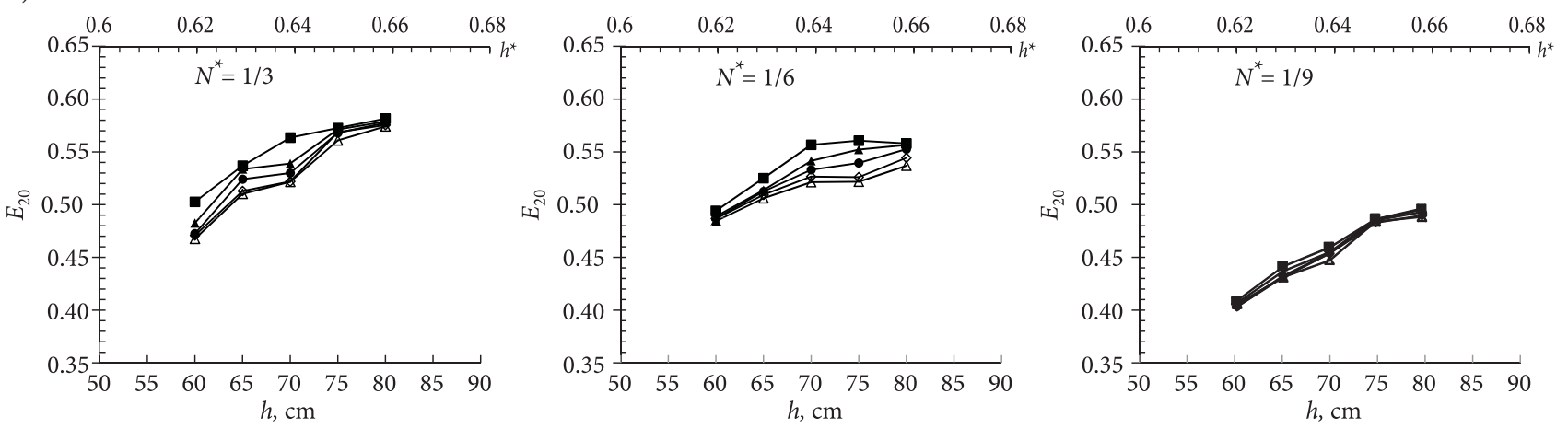

$\rightarrow Q=0.41 / s \rightarrow Q=0.61 / s \rightarrow Q=0.81 / s \rightarrow Q=1.01 / s \quad \rightarrow Q Q=1.21 / s$

Fig. 6. Variation of oxygen-transfer efficiency $E_{20}$ in interlaced flashboard spillways: (a) $E_{20}$ vs. Q; (b) $E_{20}$ vs. $h$

spillways under different flow conditions are displayed in Figure 7. There are $15 \mathrm{sub}$-graphs corresponding respectively to the 15 different combinations of $Q(0.4 \mathrm{l} / \mathrm{s}, 0.6 \mathrm{l} / \mathrm{s}$, $0.8 \mathrm{l} / \mathrm{s}, 1.0 \mathrm{l} / \mathrm{s}$ and $1.2 \mathrm{l} / \mathrm{s})$ with $N^{*}(1 / 3,1 / 6$, and $1 / 9)$, each one of which exhibits the values of $E_{20}$ in 15 experimental runs of 5 different $h^{*}(0.606,0.623,0.638,0.653$ and 0.667$)$ by 3 spillways respectively, for a particular combination of $Q$ and $N^{*}$. Flashboard spillways significantly outperformed smooth ones, with average increases in aeration performance $\left(E_{20}\right)$ of $271.6-376.1 \%$ for parallel flashboard spillways and 286.4-402.3\% for interlaced flashboard spillways. The flashboards strongly disturb and convert the skimming flow into a kind of milky and non-transparent gas-liquid mixture. They act like a series of air-entrainment points, greatly enhancing aeration efficiency in the spillway. It was thereby demonstrated that mounting flashboards on a spillway may indeed be an effective measure for promoting its aeration capability for water flowing through the overflow dam.

Calculated from Figure 7, the differences in $E_{20}$ between the parallel and interlaced flashboard spillways range from 0.00044 to 0.0719 , much less than those between the flashboard and smooth spillways which are 0.276-0.424. $E_{20}$ levels in the parallel and interlaced flashboard spillways are almost the same at $N^{*}=1 / 9$.
With increasing $N^{*}$, the interlaced flashboard spillway appears to offer slightly higher aeration efficiency than the parallel one.

Figure 8 illustrates the variations in oxygen-transfer efficiency $E_{20}$ for different $N^{*}$ in the parallel and interlaced flashboard spillways separately under the test condition $Q=0.4 \mathrm{l} / \mathrm{s}$ (similar patterns have been found under other discharge rates), where $N^{*}=0$ represents a smooth spillway. A significant rise in $E_{20}$ is apparent between the smooth spillway and the $N^{*}=1 / 9$ flashboard spillway because of the transition of overflow regime from skimming flow with a distinct free surface over the smooth spillway to a strongly discontinuous and turbulent nappe flow over the flashboard spillway. A relatively smooth improvement in aeration performance of the spillway then takes place, with a continuously declining growth rate as the number of flashboards increases.

Histograms of $E_{20}$ growth rate with $N^{*}$ under $Q=$ $0.4 \mathrm{l} / \mathrm{s}$ (similar patterns were observed under other discharge rates) in the parallel and interlaced flashboard spillways are shown in Figure 9. As shown, the growth rate in $E_{20}$ decreases sharply with increasing $N^{*}$. As $N^{*}$ increases from 0 to $1 / 9$, the growth rate of $E_{20}$ reaches almost 3.0, but it decreases to less than 0.1 when $N^{*}$ increases from $1 / 6$ to $1 / 3$. It can be assumed that $E_{20}$ would tend towards stability if $N^{*}$ 

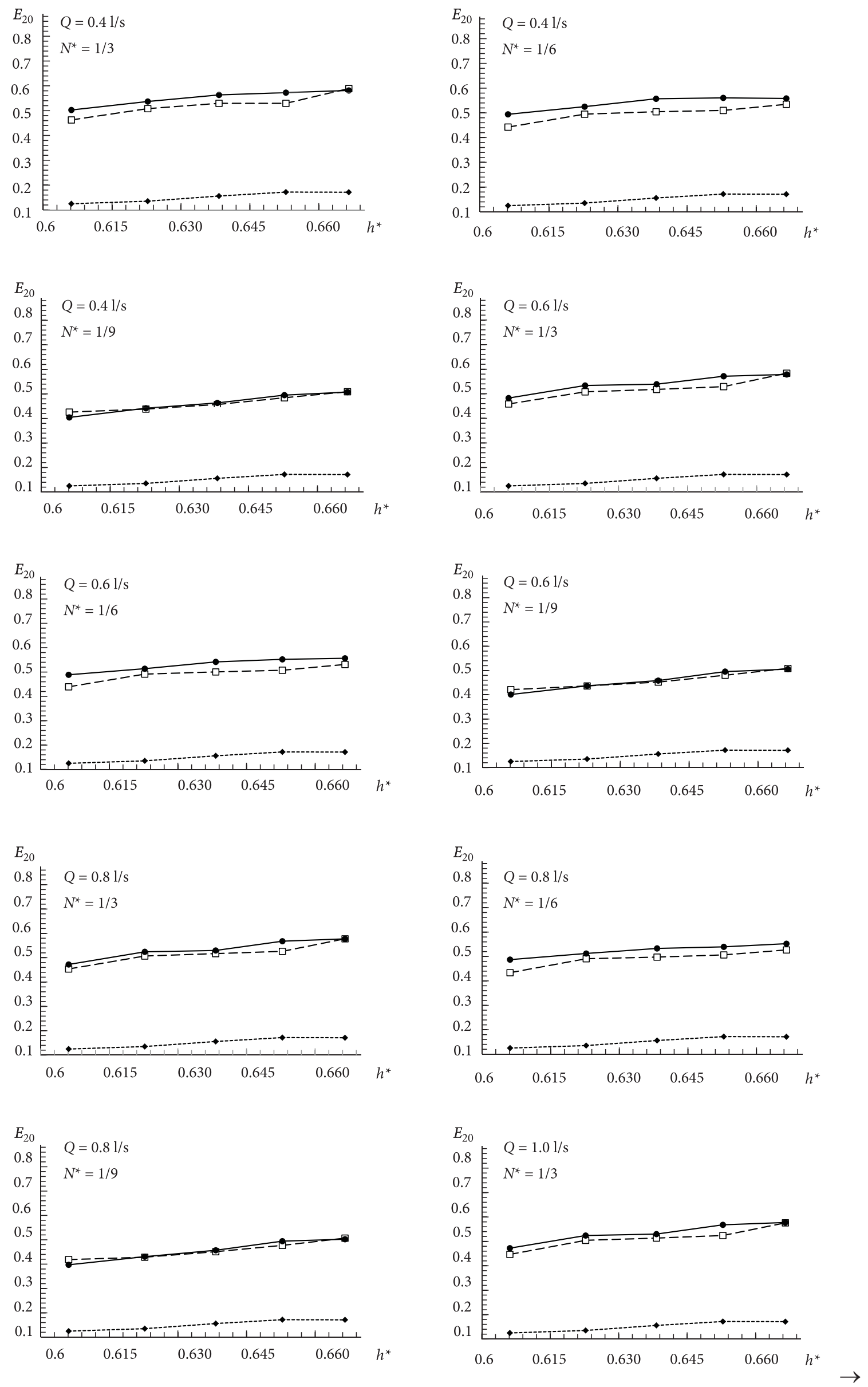

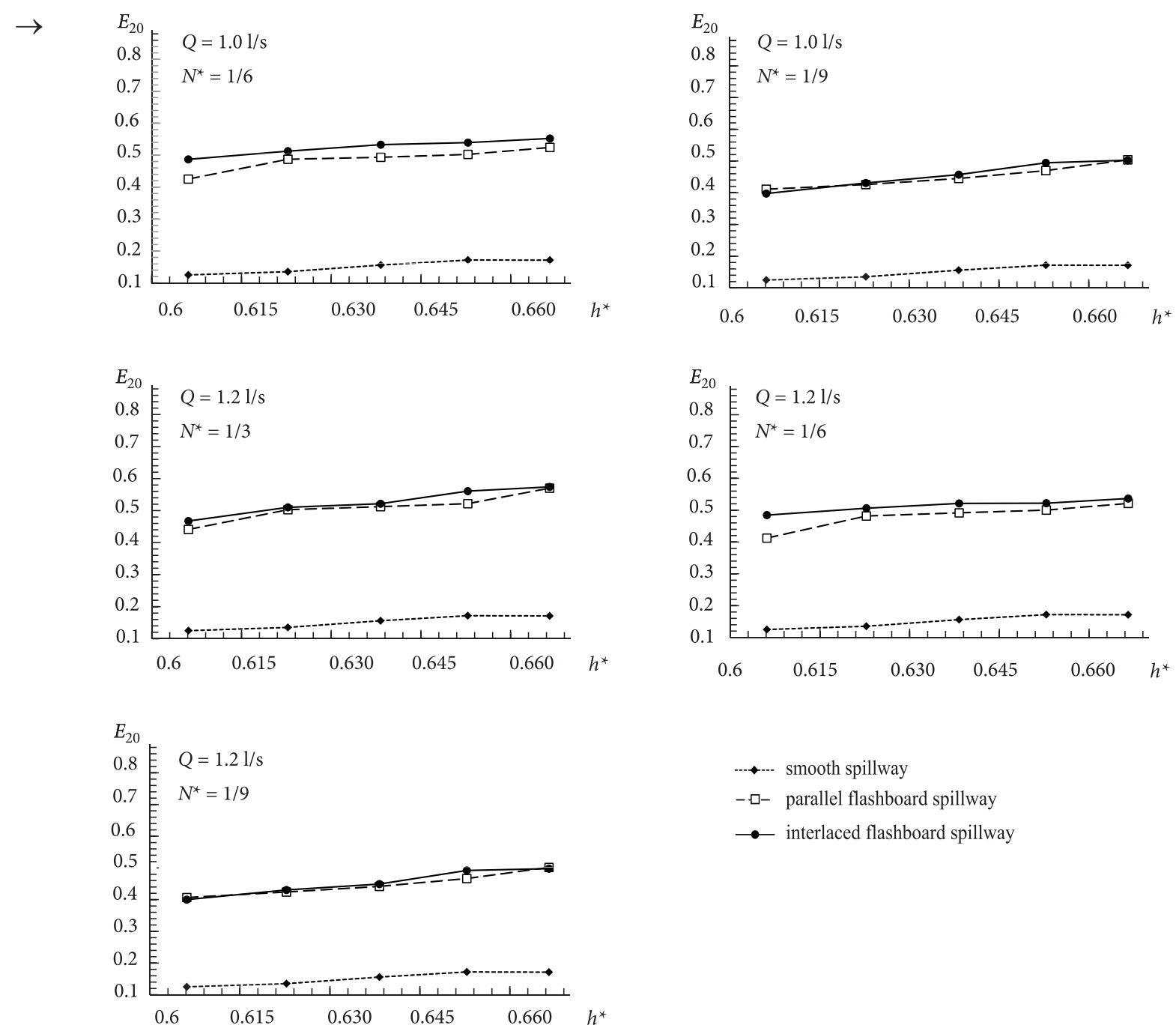

Fig. 7. Comparison between $E_{20}$ in parallel flashboard and inter-laced flashboard spillways

exceeded $1 / 3$ for the overflow dam with flashboard spillway.

Fig. 10 presents the change trend with $\Psi$ of the oxygen-transfer efficiency $E_{20}$ for flashboard spillways with different values of $N^{*} . E_{20}$ also decreases with $\Psi$ according to a power law. By multivariate regression analysis, the following empirical formulae for oxygen-transfer efficiency at the flashboard spillway were determined:

1) parallel flashboard spillway:

$$
E_{20}=0.0428 \cdot \Psi^{-0.5} \cdot 0.980^{\left(1 / N^{*}\right)} ; R^{2}=0.924,
$$

2) interlaced flashboard spillway:

$$
E_{20}=0.0458 \cdot \Psi^{-0.5} \cdot 0.975^{\left(1 / N^{\star}\right)} ; R^{2}=0.909 .
$$

Thus, by knowing the number of flashboards $(N)$, the discharge per unit width $(q)$, the water depth on the crest $\left(h_{d}\right)$, and the total height of the spillway $(h)$ the overall aeration efficiency of the spillway at $20^{\circ} \mathrm{C}\left(E_{20}\right)$ can be determined.

It can be deduced from Eqns (12) and (13) that $E_{20}$ decays gradually to stability with increasing $\Psi$ with a fixed number of flashboards in the spillway, and also that $E_{20}$ grows to another stable value with increasing $N^{*}$ when $\Psi$ is maintained constant. Figure 11 shows the oxygen-transfer efficiency $E_{20}$ as a function of $\Psi$ for a particular $N^{*}$, as well as $E_{20}$ for a particular $\Psi$ as a function of $N^{*}$. On the one hand, the delta $E_{20}$ between the interlaced and parallel flashboard spillways is slightly affected by variation in $\Psi$ when $N^{*}$ remains constant (Figure 11(a)); on the other hand, for a particular $\Psi$, the delta $E_{20}$ goes to zero for $N^{\star} \leq 0.1$, increases smoothly as $N^{*}$ increases from 0.1 to approximately 0.4 , and gradually stabilizes after $N^{*}$ exceeds 0.4 (Figure 11(b)).

\section{Conclusions}

Laboratory experiments were carried out to investigate the aeration performance of overflow dams with a curved surface and three types of spillways: smooth, parallel flashboard, and interlaced flashboard, over a range of flow from 0.4 to $1.2 \mathrm{l} / \mathrm{s}$ and with total spillway heights from 0.60 to 


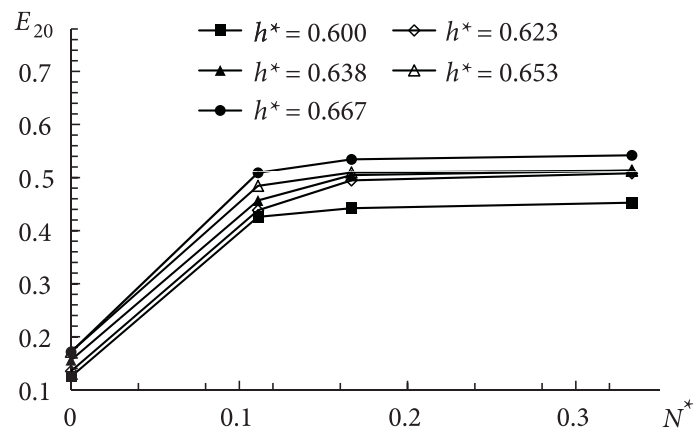

a)

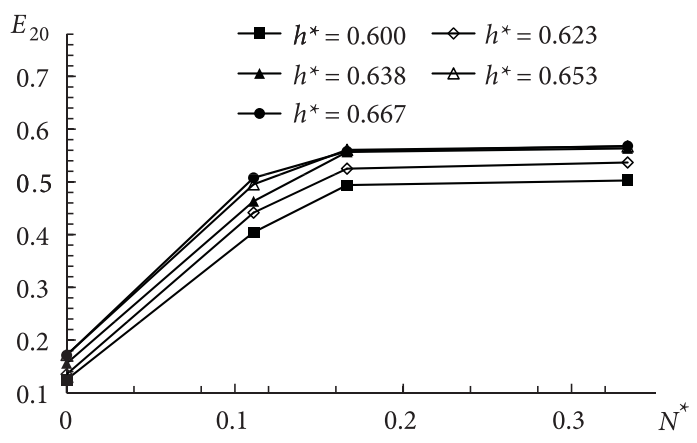

b)

Fig. 8. Variation of $E_{20}$ with $N^{*}$ when $Q=0.4 \mathrm{l} / \mathrm{s}$ in: (a) parallel flashboard spillways; (b) interlaced flashboard spillways

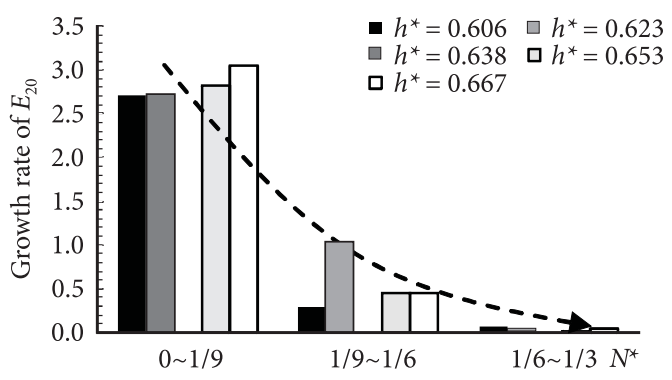

a)

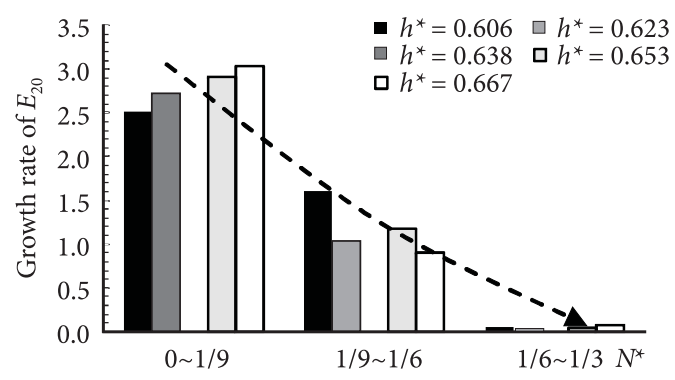

b)

Fig. 9. Growth rate of $E_{20}$ with $N^{*}$ when $Q=0.4$ l/s in: (a) parallel flashboard spillways; (b) interlaced flashboard spillways

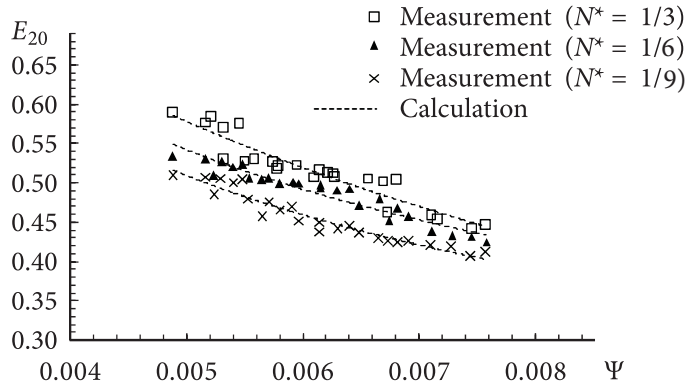

a)

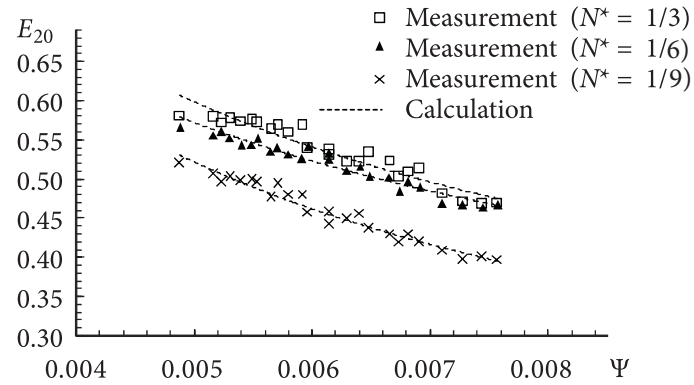

b)

Fig. 10. Relationships between $E_{20}$ and $\Psi$ for: (a) parallel flashboard spillways; (b) interlaced flashboard spillways

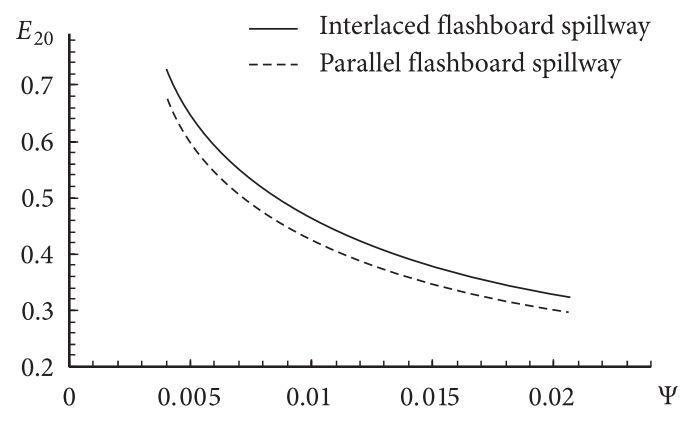

a)

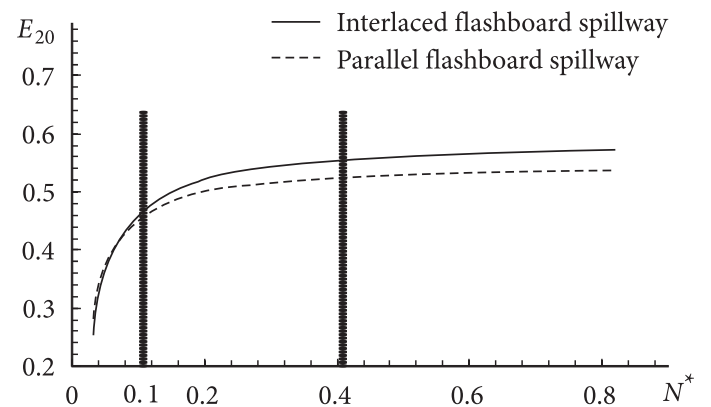

b)

Fig. 11. $E_{20}$ of flashboard spillways as a function of: (a) $\Psi$ for a particular $N^{*}$; (b) $N^{*}$ for a particular $\Psi$ 
$0.80 \mathrm{~m}$. A new dimensionless parameter $\Psi$ was created to characterize the comprehensive effects on aeration of the hydraulic conditions of the overflow. Empirical correlations predicting the aeration efficiency of these differently shaped spillways on the overflow dam have been developed. The following conclusions can be drawn:

(1) Flashboard spillways significantly outperformed smooth ones in aeration performance $\left(E_{20}\right)$ with average increases of $271.6-376.1 \%$ and $286.4-402.3 \%$ for parallel and interlaced flashboard spillways respectively. Note that the value $E_{20}$ of the interlaced one is slightly higher than the parallel one. $E_{20}$ increases as the dimensionless number of flashboards per unit area of spillway $N^{*}$ increases at the growth rate declining sharply with $N^{*}$. Furthermore, $E_{20}$ decreases with $\Psi$ in the negative power-law relationship. Empirical formulas for predicting $E_{20}$ in spillways as a function of $\Psi$ and $\mathrm{N}^{*}$ were established separately, the properties of which indicate that $E_{20}$ will achieve stability with increasing $\Psi$ or $N^{*}$ in isolation.

(2) Laboratory investigations demonstrated that installing flashboards in a spillway is an efficient method of promoting aeration performance at an overflow dam because of the strong turbulent mixing and air-entrainment points created in the overflow by the flashboards. Stream water flowing through a flashboard spillway is much more highly aerated than water flowing through a conventional smooth one. The work can be used for overflow dams with a curved surface optimally designed in terms of aeration efficiency.

\section{Acknowledgments}

This work was financially supported by the National Key Technology R\&D Program (Grant No. 2012BAB03B04), Major Science and Technology Program for Water Pollution Control and Treatment (2012ZX07103-005), National Nature Science Foundation of China (Grant No. 51179052, 51379060 and 51009048), Natural Science Foundation of Jiangsu Province of China (BK20130828), Ministry of Water Resources' Special Funds for Scientific Research on Public Causes (201001028) and the Project of "Six Talent Peak" of Jiangsu Province (08-C).

\section{References}

Aras, E.; Berkun, M. 2010. Comparison of stepped and smooth spillway effects on stream reaeration, Water SA 36(3): 309313.

Bagatur, T. 2009. Evaluation of preaeration with V-Notch Weir and cascade structures in clarifiers, Journal of Environmental Engineering ASCE 135(3): 176-184. http://dx.doi.org/10.1061/(ASCE)0733-9372(2009)135:3(176)

Baylar, A.; Bagatur, T.; Emiroglu, M. E. 2007. Prediction of oxygen content of nappe, transition, and skimming flow regimes in stepped-channel chutes, Journal of Environmental Engineering and Science 6(2): 201-208. http://dx.doi.org/10.1139/s06-048

Baylar, A.; Emiroglu, M. E. 2003. Study of aeration efficiency at stepped channels, Proceedings of the Institution of Civil Engineers-Water Management 156(3): 257-263. http://dx.doi.org/10.1680/wame.2003.156.3.257

Baylar, A.; Emiroglu, M. E.; Bagatur, T. 2006. An experimental investigation of aeration performance in stepped spillways, Water and Environment Journal 20(1): 35-42. http://dx.doi.org/10.1111/j.1747-6593.2005.00009.x

Baylar, A.; Unsal, M.; Ozkan, F. 2010. Hydraulic structures in water aeration processes, Water Air and Soil Pollution 210(1-4): 87-100. http://dx.doi.org/10.1007/s11270-009-0226-2

Chanson, H. 2009.Turbulent air-water flows in hydraulic structures: dynamic similarity and scale effects, Environmental Fluid Mechanics 9(2): 125-142. http://dx.doi.org/10.1007/s10652-008-9078-3

Chanson, H.; Toombes, L. 2002. Energy dissipation and air entrainment in stepped storm waterway: experimental study, Journal of Irrigation and Drainage Engineering 128(5): 305-315. http://dx.doi.org/10.1061/(ASCE)07339437(2002)128:5(305)

Crookston, B. M.; Tullis, B. P. 2013. Hydraulic design and analysis of labyrinth weirs. II: nappe aeration, instability, and vibration, Journal of Irrigation and Drainage Engineering ASCE 139(5): 371-377. http://dx.doi.org/10.1061/(ASCE)IR.1943-4774.0000553

Dalla Santa, K.; Vinatea, L. 2007. Evaluation of respiration rates and mechanical aeration requirements in semi-intensive shrimp Litopenaeus vannamei culture ponds, Aquacultural Engineering 36(1): 73-80. http://dx.doi.org/10.1016/j.aquaeng.2006.07.002

Dong, C.; Zhu, J.; Miller, C. F. 2009. Evaluation of six aerator modules built on venturi air injectors using clean water test, Water Science \& Technology 60(5): 1353-1359. http://dx.doi.org/10.2166/wst.2009.420

Emiroglu, M. E.; Baylar, A. 2003. An investigation of effect of stepped chutes with end sill on aeration performance, Water Quality Research Journal of Canada 38(3): 527-539.

Felder, S.; Chanson, H. 2009. Energy dissipation, flow resistance and gas-liquid interfacial area in skimming flows on moderate-slope stepped spillways, Environmental Fluid Mechanics 9(4): 427-441. http://dx.doi.org/10.1007/s10652-009-9130-y

Ghaly, A.; Thistle, A. 2009. Performance evaluation of an oxidation ditch system with a disc aerator, American Journal of Applied Sciences 8(7): 662-674. http://dx.doi.org/10.3844/ajassp.2011.662.674

Ghare, A. D.; Wadhai, P. J.; Mistry, N. J.; Porey, P. D. 2008. Hydraulic and environmental aspects of long crested weirs, Global Journal of Environmental Research 2(3): 122-125.

Gulliver, J. S.; Thene, J. R.; Rindels, A. J. 1990. Indexing gas transfer in self-aerated flows, Journal of Environmental Engineering 116(3): 503-523.

http://dx.doi.org/10.1061/(ASCE)0733-9372(1990)116:3(503)

Kramer, K.; Hager, W. H. 2005. Air transport in chute flows, International Journal of Multiphase Flow 31(10-11): 1181-1197. http://dx.doi.org/10.1016/j.ijmultiphaseflow.2005.06.006 
Kumar, A; Moulick, S; Mal, B. C. 2010. Performance evaluation of propeller-aspirator-pump aerator, Aquacultural Engineering 42(2): 70-74.

http://dx.doi.org/10.1016/j.aquaeng.2009.12.001

Moulick, S.; Mal, B. C. 2009. Performance evaluation of doublehub paddle wheel aerator, Journal of Environmental Engineering ASCE 135(7): 562-566.

http://dx.doi.org/10.1061/(ASCE)0733-9372(2009)135:7(562)

Moulick, S.; Tambada, N. V.; Singh, B. K.; Mal, B. C. 2010. Aeration characteristics of a rectangular stepped cascade system,
Water Science \& Technology 61(2): 415-420. http://dx.doi.org/10.2166/wst.2010.828

Takahashi, M.; Ohtsu, I. 2012. Aerated flow characteristics of skimming flow over stepped chutes, Journal of Hydraulic Research 50(4): 427-434. http://dx.doi.org/10.1080/00221686.2012.702859

Toombes, L.; Chanson, H. 2005. Air-water mass transfer on a stepped waterway, Journal of Environmental Engineering ASCE 131(10): 1377-1386.

http://dx.doi.org/10.1061/(ASCE)0733-9372(2005)131:10(1377)

Kejian CHU. PhD, College of Environment, Hohai University. He has published about 30 academic papers, 3 monographs, and attended 6 international conferences in recent years. Research interests include water cleaning technologies, contaminant transport modelling and simulation, and environmental impact assessment

Zulin HUA. PhD, College of Environment, Hohai University. He has published more than 60 academic papers, 3 monographs, and attended 10 international conferences in recent years. Research interests include water environment treatment and water environment simulation.

Lijun JI. Master, College of Environment, Hohai University. Her research interests include water cleaning technologies and $\mathrm{cm}$ environmental processes modelling. 